\title{
Komposisi Jenis dan Kepadatan Sponge (Porifera: Demospongiae) di Kepulauan Spermonde Kota Makassar
}

Species Composition and Density of Sponges (Porifera: Demospongiae) around Spermonde Archipelago of Makassar City

\author{
Abdul Haris ${ }^{1}$, Shinta Werorilangi ${ }^{1}$, Sulaiman Gosalam ${ }^{1}$, dan Andry Mas'ud ${ }^{2}$ \\ ${ }^{1}$ Jurusan Ilmu Kelautan, FIKP, Universitas Hasanuddin Makasar \\ ${ }^{2}$ Program Magister Ilmu Perikanan, Universitas Hasanuddin Makasar \\ E-mail:haris_pagala@yahoo.co.id*Penulis untuk korespondensi
}

\begin{abstract}
Sponge is one of the components on the coastal and marine ecosystems, especially coral reefs and seagrass beds. Climate change and environmental conditions can affect the life of the sponge. The study is conducted to determine the distribution of the composition and density of sponge using belt transects (transect quadrant) with a size of $5 \times 5 \mathrm{~m}$, then count the number of each type of sponge contained in the transect. Study site divided into three (3) zones indicating different conditions of eutrophication. A total of 49 species were identified from 16 families of 8 orders. Composition and density of the sponge in inner zone as many as 11 families with a density of $0.96 \mathrm{ind} / \mathrm{m} 2$, and lower compared to the composition and density in the middle zone and outer zone. This is related to the difference in environmental conditions of the three zones based on eutrophication conditions.
\end{abstract}

Keywords: Sponge, species composition, density, spermonde

\begin{abstract}
Abstrak
Sponge merupakan salah satu penyusun pada ekosistem pesisir dan laut, terutama pada ekosistem terumbu karang dan padang lamun. Perubahan iklim dan kondisi lingkungan dapat mempengaruhi kehidupan dari sponge. Maka dilakukan penelitian untuk mengetahui sebaran komposisi dan kepadatan sponge menggunakan metode transek belt (transek kuadran) dengan ukuran $5 \times 5 \mathrm{~m}$, kemudian menghitung jumlah dari setiap jenis sponge yang terdapat dalam transek. Lokasi penelitian terbagi atas 3 (tiga) zona eutrofikasi yang menunjukkan kondisi eutrofikasi yang berbeda. Sebanyak 49 spesies yang teridentifikasi berasal dari 16 famili 8 ordo. Komposisi dan Kepadatan sponge pada zona dalam sebanyak 11 famili dengan kepadatan 0,96 ind $/ \mathrm{m}^{2}$, lebih rendah dibandingkan dengan komposisi dan kepadatan pada zona tengah dan zona luar. Hal tersebut terkait dengan adanya perbedaan kondisi lingkungan dari ketiga zona yang terbagi berdasarkan kondisi eutrofikasi tersebut.
\end{abstract}

Kata kunci: Sponge, komposisi jenis, kepadatan, spermonde

Diterima: 25 Oktober 2013, disetujui: 06 Desember 2013

\section{Pendahuluan}

Di dunia terdapat sekitar 10.000 spesies sponge, di Indonesia diperkirakan sebanyak 850 spesies (van Soest, 1989) sampai 1500 spesies (Hooper dan van Soest, 2002). Sponge atau porifera adalah hewan dari phylum porifera yang merupakan salah satu hewan primitif yang hidup menetap dan bersifat filter feeder. Sponge memompa air keluar melalui tubuhnya dan menyaring partikel sebagai bahan makanan
(Hickman dkk., 2002). Secara ekologi, sponge merupakan salah satu penyusun pada ekosistem pesisir dan laut, terutama pada ekosistem terumbu karang dan padang lamun yang umumnya dijumpai di perairan tropik dan subtropik (Haris, 2013; Samawi dkk., 2009). Kepulauan Spermonde merupakan kepulauan yang terdiri dari gugus pulau dan jaraknya terpisah antara satu pulau dengan pulau yang lainnya. Perubahan iklim dan kondisi lingkungan dapat mempengaruhi kehidupan dari 
sponge yaitu peningkatan suhu permukaan laut, peningkatan eutrofikasi, perubahan struktur trofik, dan peningkatan bio-erosi (Holmes, 2000; Rani, 2010). Sehingga kondisi komposisi dan kepadatan sponge pada suatu wilayah perlu diketahui dengan melakukan identifikasi keragamannya.

Mengidentifikasi sponge, perlu juga diketahui kondisi oceanografi fisika kimia perairan. Nutrien yang menjadi tolok ukur pada terjadinya eutrofikasi adalah nitrat dan fosfat, yang juga sangat terkait dengan beberapa parameter oseanografi lainnya, sehingga wilayah dengan kondisi perairan yang eutrofik akan mengalami degradasi (Pawlak dkk., 2009). Untuk itu diperlukan berbagai referensi tentang kondisi sponge dengan melakukan identifikasi komposisi dan kepadatan sponge di wilayah kepulauan spermonde kota makassar, saat ini literatur-literatur penelitian tentang identifikasi sponge diwilayah tersebut masih sangat kurang.

\section{Metode Penelitian}

Penelitian ini dilakukan pada bulan Juli 2013 dengan pengambilan lokasi di beberapa pulau pada tingkat eutrofikasi yang berbeda di Perairan Kepulauan Spermonde Kota Makassar Sulawesi Selatan, mewakili zona luar yaitu pulau Lajukkang dan pulau Langkai, Mewakili zona tengah yaitu pulau Barranglompo, pulau Bonebatang dan pulau Kodingareng Keke, sedangkan untuk zona dalam diwakili oleh pulau
Samalona, pulau Lae-lae dan pulau Kayangan. Peta menurut pembagian Zonasi Eutrofikasi oleh Faizal (2011) didapatkan seperti pada Gambar 1.

Alat yang digunakan selama penelitian adalah perahu motor sebagai alat transportasi ke stasiun penelitian, peralatan Scuba untuk menyelam, GPS (Global Positioning System) untuk penentuan titik koordinat stasiun penelitian, alat tulis bawah air (sabak) untuk mencatat data saat pengamatan, kamera bawah air untuk dokumentasi penelitian, roll meter untuk pemasangan transek garis, kantong sampel untuk memasukan sampel, buku kategori sponge untuk panduan identifikasi Sponge.

\section{Identifikasi Sponge}

Dalam penelitian ini akan dilakukan proses identifikasi berdasarkan kriteria spesies yang dibuat oleh beberapa pakar yaitu secara mata telanjang (makroskopis) berdasarkan lokasi, bentuk luar, ukuran, oscula, konsistensi, permukaan dan warna. Kemudian dilakukan juga identifikasi secara mikroskopis (de Voogd, 1997; Amir dan Budiyanto, 1996; Hooper, 2003; Haris, 2013). Untuk menentukan kepadatan sponge dilakukan dengan metode transek belt $5 \times 5 \mathrm{~m}$ sebanyak 8 kali ulangan dengan interval setiap 10 meter dengan panjang transek 100 meter. Langkah-langkahnya dengan membuat transek pada tiap 4 stasiun pengamatan setiap pulau dan menggunakan GPS tegak lurus untuk mengetahui letak setiap stasiun penelitian.

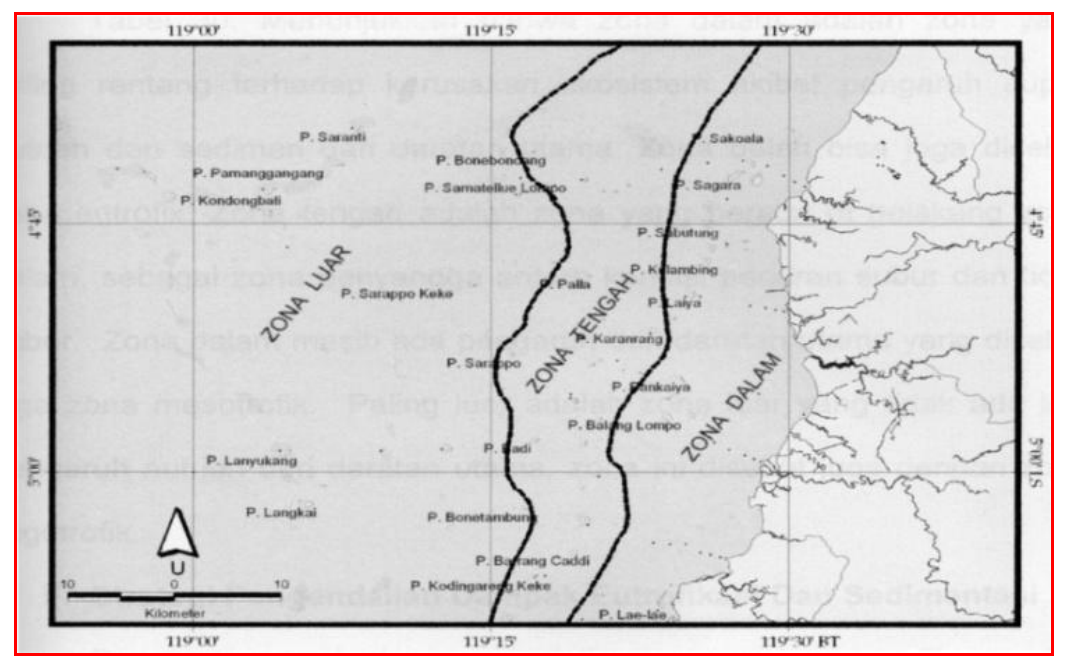

Gambar 1. Lokasi penelitian di zonasi eutrofikasi kepulauan Spermonde (Faizal, 2011). 


\section{Komposisi Jenis dan kepadatan Sponge}

Untuk mengetahui data komposisi jenis dan kepadatan sponge, dilakukan pemasangan transek belt (transek kuadran) dengan ukuran 5x5 m, kemudian menghitung jumlah dari setiap jenis sponge yang terdapat dalam transek. Transek diletakkan sepanjang garis transek sejauh $55 \mathrm{~m}$ dimulai dari titik $0 \mathrm{~m}$ dengan interval $10 \mathrm{~m}$.

\section{Analisis Data}

Dalam menghitung komposisi jenis sponge digunakan rumus sebagai berikut (Odum, 1971) :

$$
\mathbf{K J}=\frac{\text { ni }}{\mathrm{N}} \times 100
$$

Keterangan :

ni $=$ Jumlah setiap genus yang teramati

$\mathrm{N}=$ Jumlah individu seluruh genus

Kepadatan Sponge dihitung berdasarkan rumus Bower dkk., 1988) yaitu:

$$
K=\frac{\mathbf{n}}{\mathbf{A}}
$$

Keterangan :

$\mathrm{K}=$ Kepadatan genus sponge

$\mathrm{n}=$ Jumlah genus sponge (ind)

$\mathrm{A}=$ Luasan transek (m2)

\section{Hasil dan Pembahasan}

\section{Komposisi Jenis dan Kepadatan Spons}

Hasil identifikasi sementara terhadap jenis sponge di lokasi penelitian, ditemukan sebanyak 49 spesies yang teridentifikasi (6 spesies belum teridentifikasi). Keseluruhan spesies berasal dari 16 famili 8 ordo (Tabel 1).

\section{Zona luar}

Berdasarkan hasil identifikasi pada pengamatan komposisi jenis sponge yang telah dilakukan, diketahui bahwa komposisi famili sponge yang tersebar di Pulau Lajukkang dan pulau Langkai di zona Luar Kepulauan Spermonde adalah Petrosidae $11,69 \%$,
Microcionidae 6,49\%, Callyspongiidae 12,98\%, Chalinidae $11,68 \%$, Niphatidae 3,89\%, Dysideidae 2,59\%, Agelasidae 7,79\%, Irciniidae $3,89 \%$, Spongidae 12,98\%, Thorectidae 3,89\%, Holicondriidae 3,89\%, Theonellida 2,59\% dan Clionidae 15,58\%. Komposisi tertinggi adalah famili Clionidae dan terendah adalah famili Dysdidae dan Theonellidae. Untuk lebih jelas dapat dilihat pada Gambar 2.

\section{Zona tengah}

Untuk hasil identifikasi pada pengamatan komposisi jenis sponge di Pulau Barranglompo, pulau bonebatang dan pulau kodingareng keke zona tengah Kepulauan Spermonde, diketahui bahwa komposisi famili sponge yang tersebar adalah Petrosidae 13,95\%, Microcionidae $4,65 \%$, Callyspongiidae $12,79 \%$, Chalinidae $18,60 \%$, Niphatidae 3,48\%, Dysdeaae 2,32\%, Agelasidae $3,48 \%$, Irciniidae $5,81 \%$, Spongidae $10,45 \%$, Thorectidae 3,48\%, Holicondriidae $1,16 \%$, Aplysinidae 1,16\%, Spirastellidae 1,16\% dan Clionidae $17,44 \%$. Komposisi tertinggi adalah famili Chalinidae dan terendah adalah famili Holicondriidae, Aplysinidae dan Spirastrellidae. Untuk lebih jelas dapat dilihat pada Gambar 3.

\section{Zona dalam}

Sedangkan untuk hasil identifikasi pada pengamatan komposisi jenis sponge di Pulau Samalona, pulau Kayangan, dan pulau Lae-lae zona tengah Kepulauan Spermonde, diketahui bahwa komposisi famili sponge yang tersebar adalah Petrosidae 3,84\%, Microcionidae 1,92\%, Callyspongiidae $17,30 \%$, Chalinidae 21,15\%, Niphatidae 7,69\%, Dysdeaae 1,92\%, Agelasidae $5,76 \%$, Spongidae 30,76\%, Holicondriidae $1,92 \%$, Clionidae $5,76 \%$ dan subertiidae $1,92 \%$. Komposisi tertinggi adalah famili Spongiidae dan terendah adalah famili Microcionidae, Dysdeidae, Holicondriidae, dan Subertiidae. Untuk lebih jelas dapat dilihat pada Gambar 4.

Dapat disimpulkan bahwa komposisi jumlah jenis sponge yang tinggi ditemukan di zona tengah yaitu pada Pulau Barranglompo, Pulau Bonebatang, dan Pulau Kodingareng keke yaitu sebanyak 14 famili dan terendah pada zona dalam di Pulau Samalona, pulau Laelae, dan pulau Kayangan yaitu terdapat 11 famili. 
Haris dkk.

Tabel 1. Taksonomi sponge yang didapatkan di Kepulauan Spermonde, Kota Makassar.

\begin{tabular}{|c|c|c|c|c|}
\hline Class & Subclass & Ordo & Famili & Species \\
\hline \multirow[t]{43}{*}{ Demospongiae } & Ceractinomorpha & Haplosclerida & Petrosidae & Xestospongia sp \\
\hline & & & & Xestospongia testudinaria \\
\hline & & & & Xestospongia muta \\
\hline & & & & Petrosia sp \\
\hline & & & & Acanthostrongylophora ingens \\
\hline & & Poecilosclerida & Microcionidae & Clathria sp \\
\hline & & & & Clathria reindwarth \\
\hline & & & & Clathria basilana \\
\hline & & & & Clathria tuberosa \\
\hline & & & Callyspongiidae & Callyspongia aerizusa \\
\hline & & & & Callyspongia sp \\
\hline & & & & Callyspongia vaginalis \\
\hline & & & Chalinidae & Haliclona $s p$ \\
\hline & & & & Haliclona cf. fascigera \\
\hline & & & & Haliclona \\
\hline & & & Niphatidae & Galliodes fibulata \\
\hline & & & & Niphates olemda \\
\hline & & & & Amphimedon viridis \\
\hline & & Dendroceratida & Dysideidae & Dysdea sp \\
\hline & & & & Dysdea etheria \\
\hline & & Agelasida & Agelasidae & Agelas tubulata \\
\hline & & & & Agelas conifera \\
\hline & & Dyctyoceratida & Irciniidae & Ircina $s p$ \\
\hline & & & & Ircina ramosa \\
\hline & & & & Ircina felix \\
\hline & & & Spongidae & Phylospongia foliances \\
\hline & & & & Carteriospongia foliances \\
\hline & & & & Phylospongia sp \\
\hline & & & & Hippospongia sp \\
\hline & & & Thorectidae & Hyrtius proteus \\
\hline & & & & Hyrtios erectus \\
\hline & & & & Hyrtius altum \\
\hline & & & & Hyrtios \\
\hline & & Halicondrida & Holicondriidae & Hymeniacidon parleve \\
\hline & & & & Svenzea plava \\
\hline & & Verongida & Aplysinidae & Aplysina sp \\
\hline & Tetractinomorpha & Hadromerida & Spirastrellidae & Spheciospongia sp. \\
\hline & & & & Spheciospongia vagabunda \\
\hline & & & Theonellidae & Theonella swinhoei \\
\hline & & & & Theonella sp. \\
\hline & & & Clionidae & Cliona vermifera \\
\hline & & & & Cliona sp \\
\hline & & & Subertiidae & Aaptos subertiodes \\
\hline
\end{tabular}




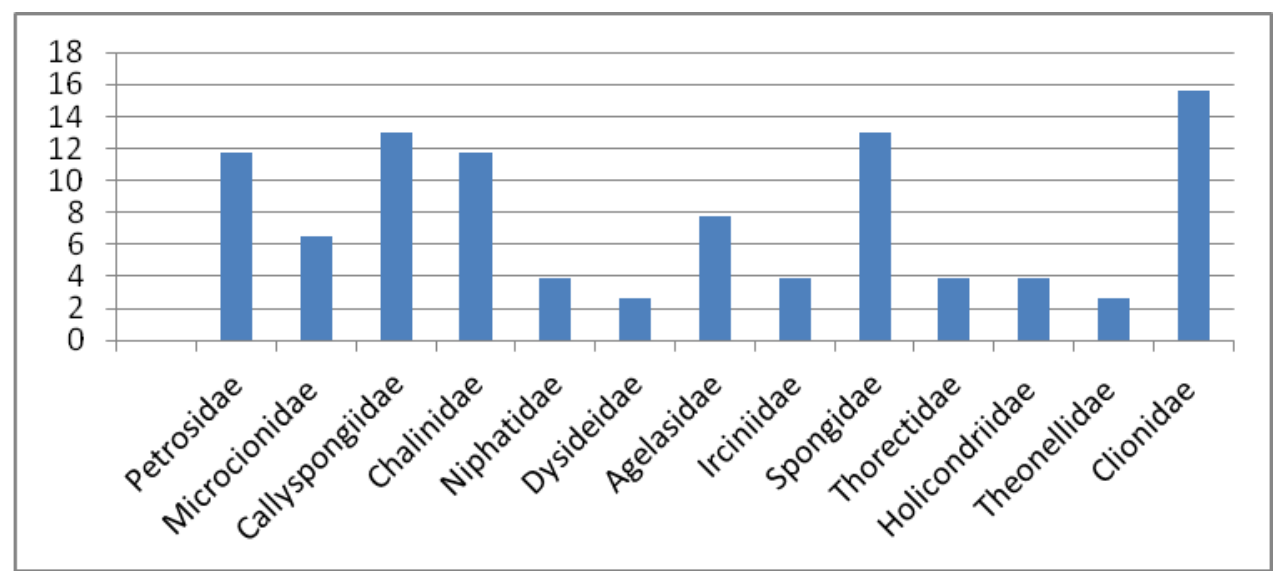

Gambar 2. Komposisi jenis sponge laut pada zona luar.

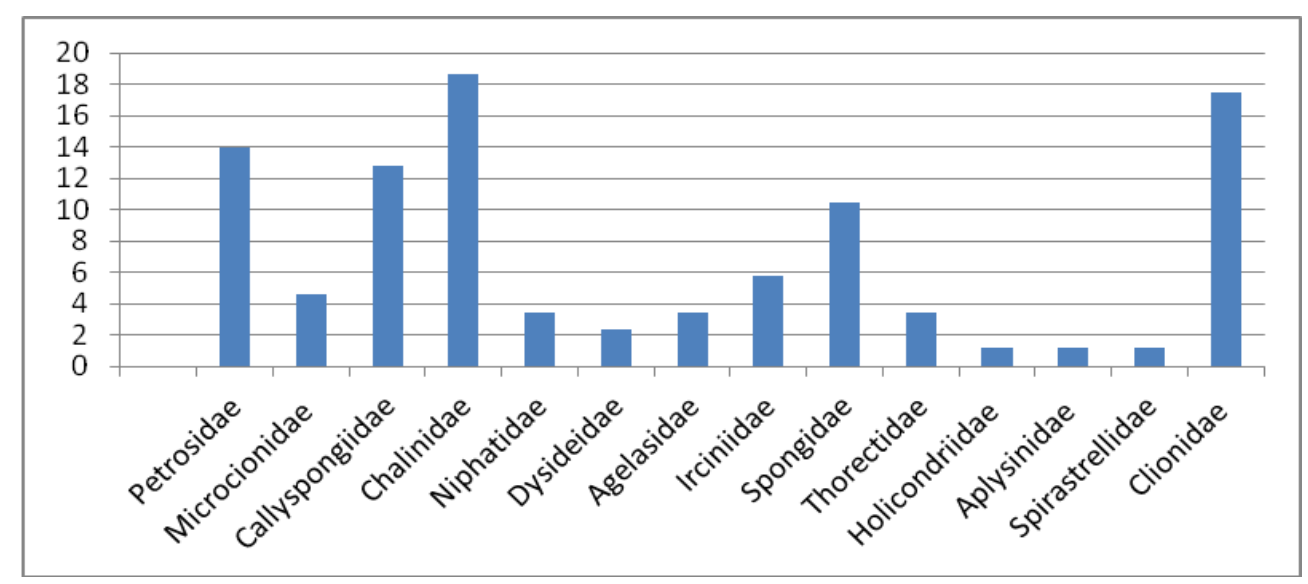

Gambar 3. Komposisi jenis sponge laut pada zona tengah.

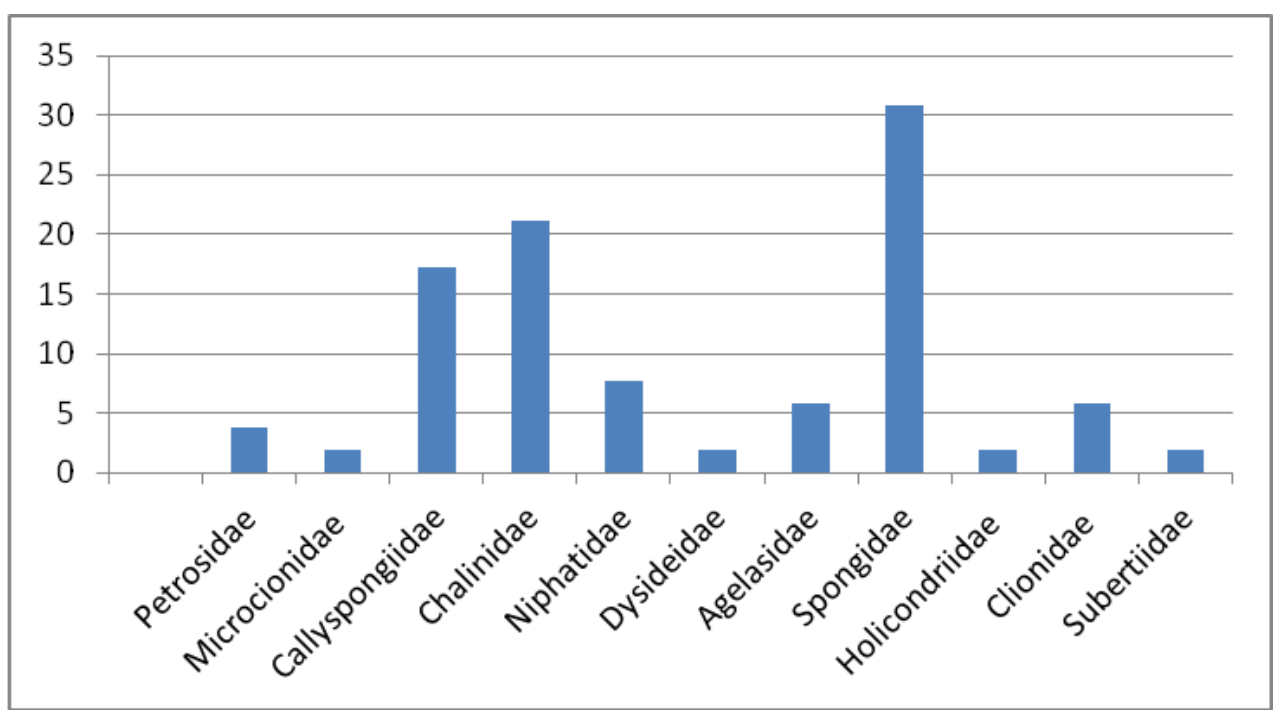

Gambar 4. Komposisi jenis sponge laut pada zona dalam. 


\section{Kepadatan}

Kepadatan rata-rata sponge antar zona didapatkan nilai yang berkisar $0,96-4,00 \mathrm{ind} / \mathrm{m}^{2}$. Kepadatan sponge di zona dalam lebih rendah dibandingkan dengan zona tengah dan zona luar yang masih relatif memiliki kondisi oceanografi yang sama. Kondisi tersebut dapat diartikan bahwa kepadatan sponge semakin beragam apabila kondisi perairan yang semakin jauh dari daratan, diperkuat dengan adanya berbagai kajian dan penelitian sebelumnya (Faizal, 2009).

Berdasarkan penelitian Faisal (2011) di Kepulauan Spermonde, didapatkan bahwa proses eutrofikasi dapat mencapai jarak 2,5-6 km dari garis pantai di Kepulauan Spermonde Kota Makassar. Aktivitas pertanian, pertambakan, industri dan rumah tangga hampir berlangsung sepanjang tahun. Aktivitas pertanian dan pertambakan tersebut banyak menggunakan pupuk organik dan non organik seperti TSP, urea, dan pupuk kandang, serta sisa pakan dari pertambakan sehingga terjadi eutrofikasi. Kepadatan sponge akan terhambat akibat dari adanya kecerahan perairan yang rendah (sedimentasi tinggi) yang diduga pengaruh dari daratan utama (Muara sungai Jeneberang) sehingga besar kemungkinan menghambat perkembangan sponge (Samawi dkk., 2009).

Terkait dengan hal tersebut maka kondisi parameter oseanografi mempengaruhi komposisi jenis sponge. Menurut Barnes (1999), sponge sangat menyukai perairan yang cukup jernih. Sponge termasuk plankton feeder, sehingga memerlukan kualitas dan kesuburan perairan yang ideal untuk menunjang kehidupannya. Selain itu suhu, arus, kekeruhan, dan salinitas merupakan faktor pembatas terhadap pertumbuhan sponge yang berpengaruh terhadap keseimbangan jumlah komposisi dan kepadatan sponge (Storr, 1976).

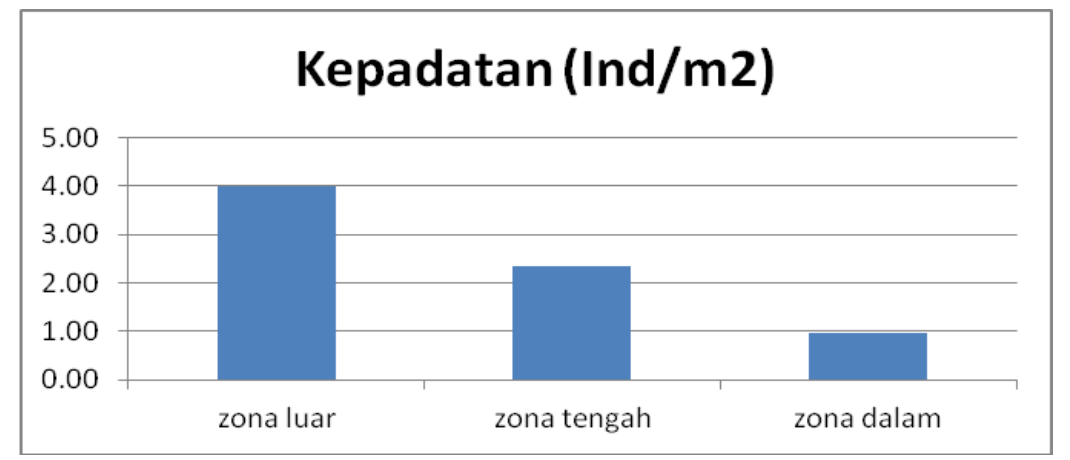

Gambar 5. Kepadatan jenis sponge laut pada zona dalam.

\section{Simpulan}

Ditemukan 49 spesies yang teridentifikasi secara keseluruhan spesies berasal dari 16 famili 8 ordo. Sponge pada zona tengah dan zona luar lebih beragam dengan adanya kondisi oceanografi yang optimal dan kedua zona tersebut mempunyai kondisi oceanografi yang relatif sama tidak terlalu berdampak terhadap kondisi perairan, zona tersebut lebih jauh dari daratan. Sedangkan kondisi sponge pada zona dalam lebih rendah komposisi dan kepadatannya yaitu sebanyak 11 famili dengan kepadatan 0,96 $\mathrm{ind} / \mathrm{m}^{2}$. Apabila dibandingkan dengan zona tengah dan zona luar di kepulauan Spermonde kota Makassar, terkait dengan adanya perbedaan kondisi lingkungan dari ketiga zona yang terbagi berdasarkan kondisi eutrofikasi tersebut.

\section{Daftar Pustaka}

Amir, I. dan Budiyanto. 1996. Mengenal Spons Laut (Demospongiae) Secara Umum. Oseana, Vol. XXI (2): 15-31.

Barnes, D.K.A. 1999. High diversity of tropical intertidalzone sponges in temperature, salinity and current extremes. Afr. J. Ecol., 37: 424-434.

Berquist, P.R. 1968. The Marine Fauna of New Zealand: Porifera, Demospongiae, Part 1 (Tetractinomorpha and Lithistida). New Zealand Department of Scientific and Industrial Research. New Zealnd Oceanographic Unstitute Memoirs, 37: 9-104. 
de Voogd, N.J.D. 1997. Cross Shelf Distribution of South West Sulawesi Open Reef Sponges. Memoir of the Queensland Museum. Australia.

Faizal, A. 2011. Dinamika Spasio-Temporal Pengaruh Eutrofikasi Sedimentasi Terhadap Degradasi Terumbu Karang. Universitas Hasanuddin. Makassar.

Haris, A. 2013. Sponge : Biologi dan Ekologi. Fakultas Ilmu Kelautan dan Perikanan - Universitas Hasanuddin, Makassar (Belum dipublikasikan).

Hickman, Roberts, dan Larson. 2002. Sponges : Phylum Porifera. Animal Diversity. Third Edition 2002. The McGraw-Hill Companies.

Hooper, J.N.A. 2003. Sponguide: Guide to Sponge Collection and Identification. Queensland Museum, PO Box 3300, South Brisbane, QLD, 4101, Australia.

Odum, E.P. 1971. Fundamental of Ecology. Third Edition. W.B. Sounder Company, Toronto.

Pawlak, J.F., Laamanen, F. dan Andersen, J.H. 2009. Eutrophication in the Baltic Sea. The Baltic Marine Environment Protection Commission Helsinki Commission - Helsinki.

Van Soest, R.W.M. 1989. The Indonesian Sponge Fauna : A Status Report. Institute of Taxonomic Zoology, University of Amsterdam, Amsterdam, The Netherlands.
Rachmaniar, R. 1996. Penelitian Produk Alam Laut Skreening Substansi Bioaktif. Laporan Penelitian Tahun Anggaran 1995/1996. Lembaga Ilmu Pengetahuan Indonesia. Puslitbang Oseanologi.

Reseck, J. Jr. 1988. Marine Biology. Second Edition. A Reston Book. Prentice Hail, Englewood Cliff., New Jersey.

Romihmohtarto, K. dan Juwana, S. 1999. Biologi Laut. Ilmu Pengetahuan tentang Biota Laut. Pusat Penelitian dan Pengembangan Oseanologi-LIPI. Jakarta. 115 - 128 .

Samawi, M.F., Rani, C. dan Ramli. 2009. Keterkaitan antara Kondisi Oseanografi dengan Komposisi Jenis dan Kepadatan Sponge Laut di Kepulauan Spermonde. Faculty of Marine Science and Fishery, Hasanuddin University. Makassar.

Storr, J.F. 1976. Ecological: Factors controlling sponge distribution in the Gulf of Mexico and the resulting zonation. Pp 261-276 in Harrison, F.W. and Cowden R.R. (eds.) Aspec of Biology. New York: Academic Press. 